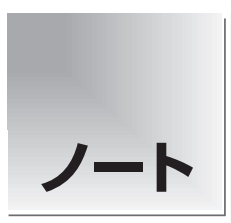

論文受付 2013 年 3 月 13 日

論文受理 2013 年 5 月 9 日

Code Nos. 151

390,922

\section{二種類の FDG-PET ガイドラインに対応した 解析ソフトウェアパッケージの開発}

松本圭一 遠藤啓吾

\section{緒 言}

陽電子放出断層撮影 (positron emission tomography: PET)は，陽電子放出核種で標識されたPET 薬剤を用 いた核医学画像診断法の一つである. ${ }^{18} \mathrm{~F}-2$-deoxy-2fluoro-D-glucose $\left({ }^{18} \mathrm{~F}-\mathrm{FDG}\right)$ を用いた PET 検査は, 組織 のグルコース代謝の充進を画像化できる唯一無二の画 像診断法であるため, 臨床的有用性の高い腫瘍診断法 として, 現在 300 施設を超える施設で施行されてい る。また, 2009 年の response evaluation criteria in solid tumor(RECIST)改訂1)によって, 近年では新しい抗がん
剂治療法の治験において ${ }^{18} \mathrm{~F}-\mathrm{FDG}$ PET 検査が評価基準 として用いられることもしばしばあり，一定の画質を保 証することがきわめて重要となってきている.

一方, PET 装置は偽の同時計数低減と高い空間分解 能を実現するためにマトリクス状に配列した小型結晶と 光電子増倍管を結合させたブロック検出器を円周上に 多数配置した構成である。このため, 他の医療機器と 比較して設置環境の影響を受けやすく, 経年変化に よっても物理学的性能が劣化するため日常の点検や性 能維持管理が重要である2,3)。また，PET装置は同じ製

\title{
Development of Analysis Software Package for the Two Kinds of Japanese Fluoro-D-Glucose-Positron Emission Tomography Guideline
}

Keiichi Matsumoto* and Keigo Endo

Department of Radiological Technology, Faculty of Medical Science, Kyoto College of Medical Science

Received March 13, 2013; Revision accepted May 9, 2013

Code Nos. 151, 390, 922

\section{Summary}

Two kinds of Japanese guidelines for the data acquisition protocol of oncology fluoro-D-glucose-positron emission tomography (FDG-PET)/computed tomography (CT) scans were created by the joint task force of the Japanese Society of Nuclear Medicine Technology (JSNMT) and the Japanese Society of Nuclear Medicine (JSNM), and published in Kakuigaku-Gijutsu 27(5): 425-456, 2007 and 29(2): 195-235, 2009. These guidelines aim to standardize PET image quality among facilities and different PET/CT scanner models. The objective of this study was to develop a personal computer-based performance measurement and image quality processor for the two kinds of Japanese guidelines for oncology ${ }^{18} \mathrm{~F}-\mathrm{FDG}$ PET/CT scans. We call this software package the "PET quality control tool" (PETquact). Microsoft Corporation's Windows ${ }^{\mathrm{TM}}$ is used as the operating system for PETquact, which requires $1070 \times 720$ image resolution and includes 12 different applications. The accuracy was examined for numerous applications of PETquact. For example, in the sensitivity application, the system sensitivity measurement results were equivalent when comparing two PET sinograms obtained from the PETquact and the report. PETquact is suited for analysis of the two kinds of Japanese guideline, and it shows excellent spec to performance measurements and image quality analysis. PETquact can be used at any facility if the software package is installed on a laptop computer.

Key words: positron emission tomography (PET), guideline, quality assurance/quality control (QA/QC), positron emission tomography (PET) quality control tool, PETquact 
造販売元であっても幾何学的な仕様や各種画像処理に 依存して画質が異なるため4), 使用する装置や被検者 の体格ごとに投与量や撮像時間を最適化する必要があ $ろ^{5)}$. 前述の背景から, PET 装置の安全性や性能維持 および標準的な画像を得ることを目的に関連学会などが 協力して二種類のガイドラインが策定され ${ }^{6,7)}$, ガイドラ インが示す推奨值を用いた撮像時間の最適化も進んで いる ${ }^{8}$.

しかし，専門的な用語や理論を主体に記述してある ガイドラインの内容を十分に理解したうえでPET 測定 とデー夕解析を行うことは, 診療放射線技師の業務が 拡大寸るなかで困難になってきていると予想される。ま た, いくつかの項目では多数の関心領域を設定して デー夕解析しなければならないため膨大な時間を必要と するだけでなく, PET 装置付属のデー夕処理部で解析 することも困難である. 日本核医学会が策定した「PET イメージングにおける撮像の標準化とデータの品質管理 および撮像の施設認証 $\rfloor^{9}$ の枠組みの中で, 装置の品質 管理および撮像法の精度管理の重要性を説いており,

PET の臨床現場で働く診療放射線技師の責務が益々大 きくなってきている.

本論文では, PET 装置付属のデー夕処理部で解析困 難であった二種類のガイドラインが規定する性能およ び画質評価項目すべてをデー夕解析して装置の品質管 理を行うとともに, 煩雑なデー夕解析が必要な撮像法の 精度管理を容易にし，かつ複数機種で測定されたデー 夕の比較検討も可能にした PET 性能・画質解析ソフト ウェアパッケージ“PET quality control tool” (PETquact) を personal computer 上で構築したので報告する.

\section{1. 方 法}

\section{1-1 開発のコンセプト}

PETquact の開発に際して, 各性能・画質評価項目お よび graphical user interface(GUI) は使用者主体で行 い, (1「FDG-PET 検査に扔ける撮像技術に関するガイ ドライン」(以下, 性能評価ガイドライン)と「がん FDGPET/CT 撮像法ガイドライン」(以下, 撮像法ガイドライ ン)に準拠した性能㧍よび画質評価解析，(2)装置固有の 処理はPET 装置付属のデー夕処理部に委ねる, (3)ガイ ドラインで正しく測定されたデー夕に対応，(4)初心者で も容易な操作性の実現, (5)関心領域の設定は簡便かつ 最小限, (6)装置の保守管理に対応, を開発のコンセプ トにした。

\section{1-2 仕様およびアプリケーション}

PETquactは，多用されているWindows NT系を



Fig. 1 An initial screen image of the PET quality control tool (PETquact) with 11 main processing buttons (left side) and menu bars (upper side).

operating system に採用し, laptop computer での使用も 想定して画面の解像度を $1070 \times 720$ 画素にした。また性 能評価ガイドラインの引用規格が National Electrical Manufacturers Association(NEMA)であり, 撮像法ガイ ドラインの概要も英文誌に掲載されていることから GUI の表記は英語表記とした，なお，プログラミング言語と して，C㧍よびVisual C++の 32 ビットプログラミング データモデルを用いた．Fig. 1 にPETquact 起動時にお ける主画面を示す，GUIは各種評価項目ボタンとメ ニューバーに大別した．画面上段に配置した“メニュー バー”には, すべての評価項目で共通となる画像読込ボ タン(Targetと Reference), Report ボタン, および画像 表示に関連するボタンを複数配置し, 画像読込ボタン を押すと画像読込プログラムが，また Report ボタンを 押すと結果報告書用のプログラムが起動する.

画面左端に縦列された各種評価項目ボタンは, 性能 評価ガイドラインで規定された性能評価 7 項目と撮像 法ガイドラインで規定された画質評価 3 項目が配置さ れ, 合計 12 種類のアプリケーションが搭載されてい る. 各種評価項目の矢印ボタンを押すことによって, 各 項目のアプリケーションが起動する。また最下部の “Setting”ボタンを押すことで, 結果報告書に記載される 情報(組織名, 装置名, 測定者名, 解析者名)を入力可 能であり, 装置名はあらかじめ設定してある 17 機種か ら選択することも可能である. Table に主要処理ボタン とその性能・画質評価項目を示す.

\section{1-3 アプリケーション例}

PETquact で解析可能な性能および画質評価項目は二 種類のガイドラインで規定された全 10 項目であるが, 
Table Button for the main process that includes various software applications

\begin{tabular}{ll}
\hline \hline Main processing buttons & Contents \\
\hline Spatial resolution & Spatial resolution \\
Scatter fraction, Count rate & Scatter fraction, Count losses, Randoms measurement \\
Sensitivity & Sensitivity \\
Uniformity & Uniformity \\
DTC, RC accuracy & Accuracy: Corrections for count losses and randoms \\
Image quality & Image quality, Accuracy of attenuation, and Scatter corrections \\
Fused image accuracy & Accuracy of image registration \\
NEC, SNR accuracy & Human PET image quality \\
Detectability & Lesion detectability \\
Recovery Coefficient & Image resolution \\
Setting & Setting of report information \\
\hline
\end{tabular}

本論文では物理学的減衰補正計算が煩雑な絶対感度 (Sensitivity)の解析と, 多数の関心領域を設定する必要 がある画像濃度の均一性(Uniformity)，第一試験 (Detectability)拉び第二試験(Recovery Coefficient)につ いて述べる。使用したPET 装置はECAT EXACT HR+ (CTI/Siemens 社 製) と Discovery PET/CT 600(General Electric Medical System 社 製)であり，次項 1-3-1 と 1-3-2 は前者の PET 装置を同じく1-3-3 と 1-3-4 は後者 を用いて測定した.

\section{1-3-1 Sensitivity}

性能評価ガイドラインにおける絶対感度評価では, 「5 本のアルミニウム管(スリーブ)の測定における各スラ イスの計数率に対して時間減衰補正を行い，2つの未 知数を持つ回帰式からシステム絶対感度を計算する」と している. PETquactでは，ガイドラインに準拠してシ ステム絶対感度を計算するだけでなく，断面視野中心 と中心から $10 \mathrm{~cm}$ の距離における内径 $3.9 \mathrm{~mm}$ のスリー ブ測定データを読み込み，各スライスの感度プロファイ ルを作成する機能を有している.

なお，三次元収集されたデー夕を解析する場合に は, PET装置付属のデー夕処理部で single slice rebinning 法を用いて傾斜サイノグラムを平行サイノグ ラムに並び替えする必要があり，また内径 $3.9 \mathrm{~mm}$ のス リーブに挿入するプラスチックチューブ内の放射能はあ らかじめ電離箱式放射能測定装置(ドーズキャリブレー 夕)を用いて測定する。

ここでは, PET 装置の性能評価の解析例として, $16.6 \mathrm{MBq}$ の ${ }^{18} \mathrm{~F}$ 溶液を封入したスリーブのデー夕に対し て PETquactを用いた絶対感度の解析を行った。

\section{1-3-2 Uniformity}

性能評価ガイドラインにおける画像濃度の均一性評 価では,「各画像スライスに, 1 辺が約 $2 \mathrm{~cm}$ の正方形関
心領域を再構成画像の辺縁から $1 \mathrm{~cm}$ 以内のすべての 領域に設定して，スライス内不均一性とシステム均一 性を算出する」としている. PETquactでは, 関心領域設 定を簡便かつ最小限にするために，画像読込が完了す ると自動的にガイドラインで規定された関心領域を設定 する機能を有している.

ここでは, $5.9 \mathrm{kBq} / \mathrm{ml}$ の ${ }^{18} \mathrm{~F}$ 溶液を封入した $20 \mathrm{~cm} \phi \times$ $20 \mathrm{~cm}$ の円筒ファントムを用いた，ガイドラインに準拠 して測定した各スライスあたり 6 メガカウントのデータ を filtered back projection 法にて画像再構成し，その画 像を PETquactに取り込んで画像濃度の均一性を解析 した。なお，PET画像のマトリクスサイズ，スライス 数，およびボクセルサイズは，それぞれ $128 \times 128 ， 63$, および $5.15 \times 5.15 \times 2.43 \mathrm{~mm}$ である.

\section{1-3-3 Detectability}

撮像法ガイドラインにおける第一試験 $(10 \mathrm{~mm}$ ホット 球描出試験)は,「当該施設における装置の機種毎に適 切な撮像条件と再構成条件を決定するために行う」とし ており，12 分間のリストモード収集データから収集開始 時刻(基準時刻，基準時刻 +1 分，基準時刻 +2 分) と収 集時間の異なる PET 画像を 30 セット再構成して物理 学的指標を算出する。物理学的指標は画素サイズを $1 \mathrm{~mm}$ 以下に補間拡大したPET 画像に対して算出す る必要があり，そのうちの\%バックグラウンド変動性 については直径 $10 \mathrm{~mm}$ の円形関心領域を合計 60 個 （12 個 ×5 スライス）設定する必要がある. PETquact で は，ホット球がもっとも明瞭に描出される 10 分収集の PET 画像の読込が完了すると自動的に画素サイズを $1 \mathrm{~mm}$ に補間拡大し, 加えてその画像に対してドロップ ダウンリストから選択した円形関心領域を一つの画像ス ライスのみに設定することで自動的に 3 種類の物理学 的指標を算出する機能を有している. 


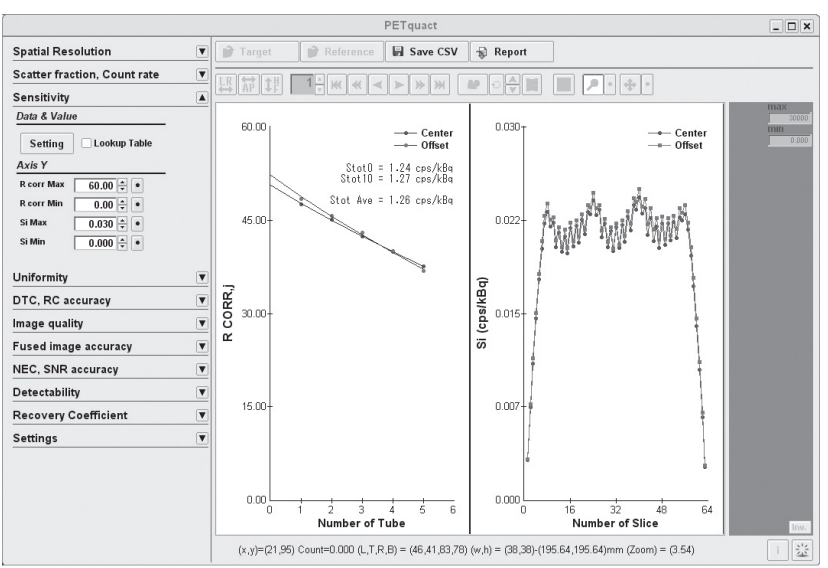

Fig. 2 Examples of sensitivity analysis for the performance measurement guideline.

ここでは, バックグラウンド領域に $5.3 \mathrm{kBq} / \mathrm{ml}$ の ${ }^{18} \mathrm{~F}$ 溶液を封入した胴体ファントムを用いて, ガイドライン に準拠したリストモード収集を行った，収集時間の異な る30セットのサイノグラムデータから ordered subsets expectation maximization(OSEM) 法にて画像再構成 し, その画像をPETquactに読み込んで $10 \mathrm{~mm}$ ホット 球描出試験を解析した。なお, PET 画像のマトリクス サイズ, スライス数, およびボクセルサイズは, それぞ れ $192 \times 192,47$ および $2.08 \times 2.08 \times 3.27 \mathrm{~mm}$ である.

\section{1-3-4 Recovery Coefficient}

撮像法ガイドラインにおける第二試験(Recovery Coefficient)の主目的は, 与えられた再構成条件が許容 される空間分解能を有するか判定するために行う. 各 ホット球にバックグラウンド領域の 4 倍放射能濃度の ${ }^{18} \mathrm{~F}$ 溶液を封入した試験ファントムを 30 分間のスタ ティック収集し, 得られたデータから $10 \mathrm{~mm}$ ホット球の リカバリ係数を算出する。 また, 前記した第一試験と同 様に画素サイズを補間拡大して円形関心領域を設定す る必要がある. PETquactでは, PET 画像の読込が完了 すると画素サイズを補間拡大して, さらに画像スライス 内の最大画素值を検出し, ホット球がもっとも明瞭に描 出された一つの画像スライスを自動的に表示する機能を 有している。不適切な画像スライスの場合には任意に 画像スライスを変更し, その画像スライスに対してド ロップダウンリストから選択した円形関心領域を設定す ることでリカバリ係数を算出する.

ここでは, バックグラウンド領域に $2.0 \mathrm{kBq} / \mathrm{ml}$ の ${ }^{18} \mathrm{~F}$ 溶液を封入した胴体ファントムを用いて，ガイドライン に準拠したスタティック収集を行った。 OSEM 法にて画 像再構成した画像を PETquactに取り込んでリカバリ係 数試験を解析した。なお, PET 画像のマトリクスサイ

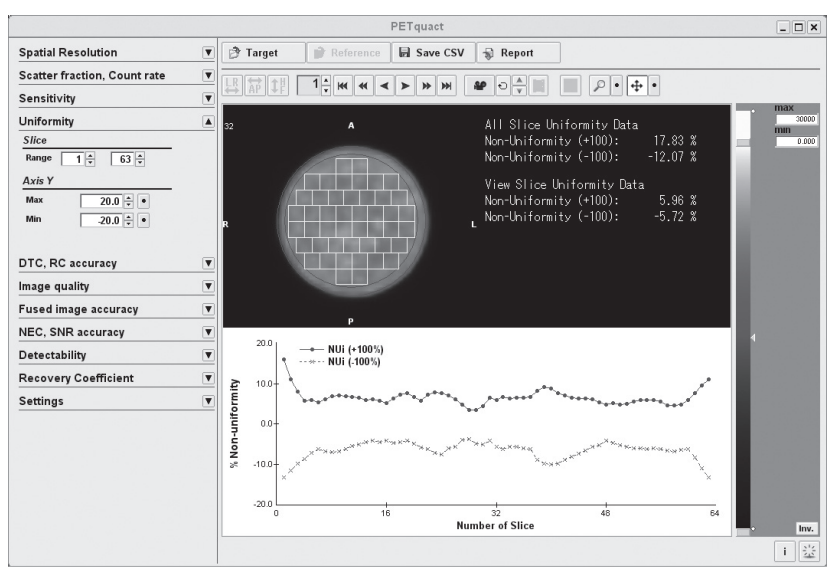

Fig. 3 Examples of uniformity analysis for the performance measurement guideline.

ズ，スライス数，およびボクセルサイズは，前項 1-3-3 と同様である.

\section{2. 結 果}

\section{2-1 Sensitivity}

Fig. 2 に絶対感度解析例の結果を示す.Fig. 2 におけ る左側のグラフは 2 カ所の測定位置で測定された各ス リーブに対する時間減衰補正済みの総計数率である. 左側のグラフ上段の数值は, 性能評価ガイドラインで 規定された回帰式を用いて算出されたシステム絶対感 度である.PETquactを用いて解析されたシステム絶対 感度は, Daube-Witherspoon ら ${ }^{10)}$ が報告した ECAT EXACT HR+の值より約 10\%高值であった．Fig. 2 にお ける右側のグラフは 2 カ所の測定值で測定された各画 像スライスにおける感度プロファイルである。体軸方向 に配置された 4 個の検出器ブロック(リング)構造を反映 し, 四つの凹凸を認めた。

\section{2-2 Uniformity}

Fig. 3 に画像濃度の均一性解析例の結果を示す. Fig. 3 における上段右の数值は性能評価ガイドラインで規定 された計算式を用いて算出されたシステム不均一性と 表示スライスの不均一性である. Fig. 3 における下段の グラフは各画像スライスにおける不均一性プロファイル である。二次元収集の特徴を反映し, 頭尾方向の画像 スライスにおける均一性が低下した。

\section{2-3 Detectability}

Fig. 4 に $10 \mathrm{~mm}$ ホット球描出試験の解析例を示す. Fig. 4 における上段の画像は，1 分収集から10 分収集 のPET 画像である. Fig. 4 における下段の表は撮像法 


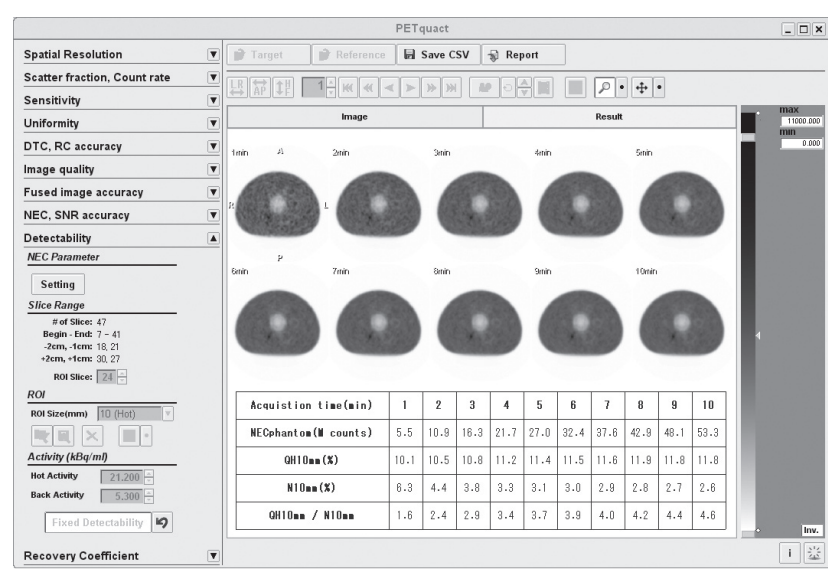

Fig. 4 Examples of phantom experiments: No.1 analysis for the data acquisition protocol guideline.

ガイドラインに準拠して自動計算された物理学的指標 である。解析時間は本例の 47 画像スライスにおいて, desktop computer[Intel Core i5-2400S $2.5 \mathrm{GHz}$ ，メモリ 4 gigabyte(GB)]で約 28 秒, laptop computer(Intel Pentium M $1.30 \mathrm{GHz}$ ，メモリ $1 \mathrm{~GB}$ )で約 58 秒であった。いずれ も 5 回測定の平均值である。撮像法ガイドラインに明記 された各種物理学的指標の推奨值と容易に比較可能で あった。

\section{2-4 Recovery Coefficient}

Fig. 5 にリカバリ係数試験の解析例を示す. Fig. 5 に 㧈ける上段左はリカバリ係数を算出した画像，同じく右 は各ホット球に対するリカバリ係数のグラフであり，下 段は各ホット球のリカバリ係数掞よび測定条件である. 撮像法ガイドラインに明記された推奨值と容易に比較 可能であった。

\section{3. 考 察}

特定保守管理医療機器のクラス II (管理医療機器)に 指定された PET(PET/CT を含む)装置のみならず，医療 機器の性能を定期的に点検・管理して正確な情報を提供 することは, 測定, 処理や解析，そして診断にとってき わめて重要であり，医療の質向上や安全性および事故防 止にも必要不可欠である。平成 19 年に医療法が改正 ${ }^{11}$ され，(1)医療機器安全管理責任者の配置，(2)従事者に 対する安全使用のための研修，(3)保守点検計画の策定 と適切な実施，(4)安全使用に必要な情報収集と安全使 用を目的とした方策，の 4 項目が医療機器の保守点検・ 安全使用に関する体制として明文化された。保守点検 は医療機関(使用者)が自ら適切に実施するべきもの ${ }^{12}$ と されているが，診療放射線技師の業務が拡大寸るなか

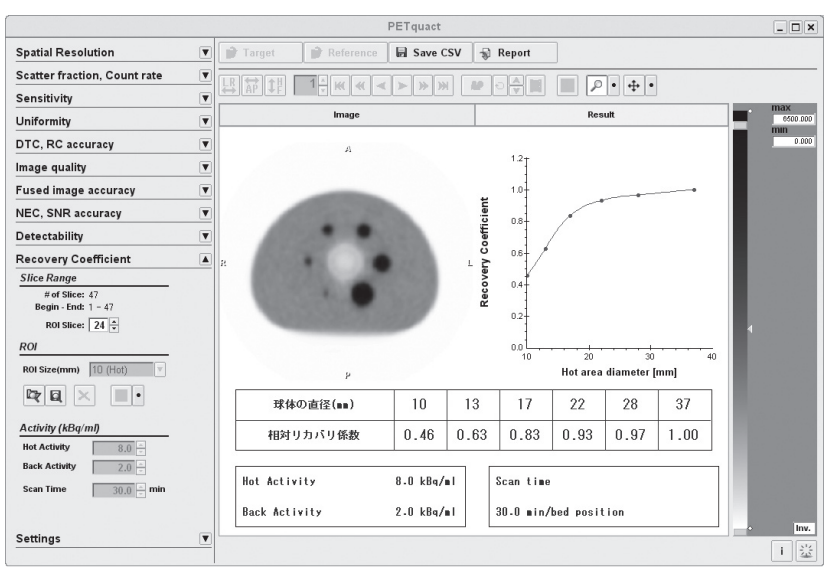

Fig. 5 Examples of the phantom experiments: No.2 analysis for the data acquisition protocol guideline.

で困難になってきていると予想される.

一方, 日本核医学技術学会と日本核医学会が合同で 作成した撮像法ガイドラインを用いて，がん FDG-PET/ $\mathrm{CT}$ 検査の標準化とデー夕の品質管理が進んでいるが, このガイドラインで定義された物理学的指標を PET 装 置付属のデー夕処理部で解析することは困難な場合が 多い. 本 PET 性能・画質解析ソフトウェアパッケージ $\lceil$ PETquact」は前記の現状を考慮し，前項 1-1で述べた 開発コンセプトをもって開発した専用のソフトウェア パッケージであり，今後ますます推進される PET 撮像 の標準化や施設認証にも有効活用されると考える.

性能評価ガイドラインで示された項目の解析は, 企 業のエンジニアや施設の研究者が開発したプログラム で行われるため, 解析結果を単純に比較することはで きない. PETquactにおける各アプリケーションは引用 規格および関連文献を参考にしてプログラム開発し, その検証は複数装置で測定されたデー夕を用いて綿密 に行ったが，本ソフトウェアパッケージで解析した絶対 感度は Daube-Witherspoon ら ${ }^{10)}$ が報告した值よりも約 10\%高值であった(Fig. 2). Daube-Witherspoon $ら^{10)}$ と Herzog ら $^{13)}$ が報告した三次元収集のシステム絶対感度 は，それぞれ $9.25 \mathrm{cps} / \mathrm{kBq}$ と $6.92 \mathrm{cps} / \mathrm{kBq}$ であり約 1.3 倍異なる。プラスチックチューブ内に封入する放射能量 は数十 $\mathrm{MBq}$ であることから放射能量測定時における測 定誤差と考えられ，Brix ら ${ }^{14)}$ が報告した収集方法の違 いによる感度差を考慮すれば信頼性の高いアプリケー ションが構築できたと考える。 また, 性能評価ガイドラ インと撮像法ガイドラインに準拠した本ソフトウェア パッケージは, 複数機種で測定されたデー夕を同一プ ラットフォームで解析できるため, 装置性能や画質の比 較検討ならびにPET 撮像の標準化に大いに活用される 
と考える.

PETquactにはレポート機能が搭載されており, 装置 の保守管理にも対応した機能が組み込まれている。絶 対感度や画像濃度の均一性のみならず, 計数率特性や 計数損失および偶発同時計数補正の精度, 被検者雑音 等価計数など (Fig. 6), 初期性能および大規模な修理後 の装置性能の管理や臨床画像デー夕の品質管理および 標準化にも有効活用できると考える。 またPETquactが 格納された DVD-Rには，各施設で頻繁に測定すること が困難なデータがサンプルデータとして添付されてお り, 各アプリケーションの理解を深めるとともに性能評 価ガイドラインの概要を理解することも可能である.

学会が撮像の施設認証を推進しているが, 撮像法ガ イドラインに対応した画像解析ソフトウェアは皆無であ る. 2013 年 3 月現在において, digital versatile disc recordable(DVD-R)に格納された本ソフトウェアパッ ケージは全国のサイクロトロン保有施設やデリバリ施設 に配布され，PET 画像の標準化や研究など種々の目的に 活用されている. 核医学関係の学術大会や研究会などで PETquactを用いた研究発表が，われわれの発表 ${ }^{15 \sim 17)}$ 以 後増加し, さらに日本放射線技術学会核医学分科会第 17 回核医学技術研究会(神奈川)で使用されるなど，わ れわれが目的とした以上の成果が達成されたと考える.

PETquactの動作環境は実用的な処理速度を保つため に, $1 \mathrm{GHz}$ 以上の動作周波数をもつ Intel Pentium 互換 プロセッサ，1 GB 以上のメモリの使用および $10 \mathrm{~GB}$ 以 上の hard disk drive(HDD)の空き容量を推奨しており laptop computerでも十分使用可能である. PET 装置で 測定されたデータをインポートしておけば，その解析場 所を選ばないことも特徵であり, 加えてサイノグラム データを直接解析する散乱フラクションと計数率特性, および絶対感度のデータインポートに関してはPET 装置 付属のデータ処理部からエクスポートした非 Digital Imaging and Communications in Medicine のサイノグラ ムデー夕にも対応していることから, PET 装置の性能評 価や画質解析をより身近なものにすることができたと考 える. 医療機器の「保守点検」は, 機器の性能を維持し て安全性を確保することによって, 医療の質向上が期 待されている. 本ソフトウェアパッケージを用いること によって, 装置の安全性や性能の維持および検査の質 を確保され，PET 画像の標準化やエビデンスの構築の 一助になることを期待するものである.

\section{4. 結 語}

がん ${ }^{18} \mathrm{~F}-\mathrm{FDG}$ PET 検査を対象とした「FDG-PET 検査 における撮像技術に関するガイドライン」と「がん FDG-

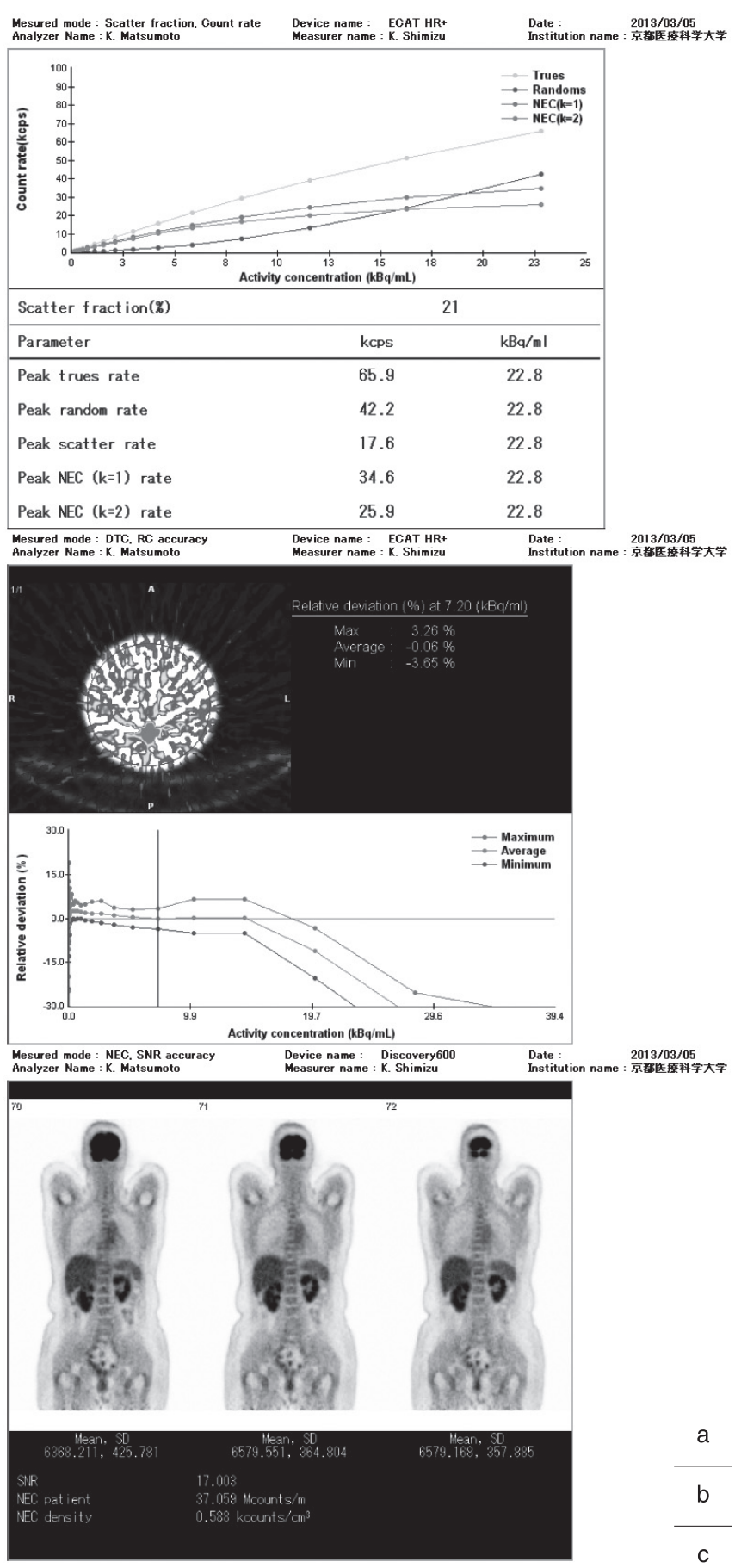

Fig. 6 Examples of the report screen image for maintenance for the two types of guideline.

(a) Examples of the scatter fraction, count losses, and random measurement analysis for the performance measurement guideline.

(b) Examples of accuracy: corrections for count losses and random analysis for the performance measurement guideline.

(c) Examples of human image quality analysis for the data acquisition protocol guideline. 
PET/CT 撮像法ガイドライン」の更なる普及を目的に, 両ガイドラインに対応したPET 性能・画質解析ソフト ウェアパッケージを開発した. PETquactは, 二種類の ガイドラインで規定されている性能および画質評価項目 すべてを解析するソフトウェアであり，PET 装置付属の デー夕処理部には搭載されていない自動関心領域設定 や保守管理用のレポート機能を搭載した，本ソフトウェ アを用いることで短時間かつ簡便に信頼性の高い解析 を行うことが可能であった。 また， PETquactは laptop computerでも十分使用可能であり，二種類のガイドラ インで規定されたPET 装置の性能評価や画質評価解析 をより身近なものにすることができた。

\section{謝 辞}

本ソフトウェアパッケージの開発や普及および本論文 作成にあたっては, 長木昭男氏(倉敷中央病院), 三村浩
朗氏(川崎医科大学附属病院), 清水敬二氏(神戸市立医 療センター中央市民病院), 谷川泰幸氏, 浜田一男氏, 大崎洋充氏(日本メジフィジックス株式会社), 菊池 敬 氏(北里大学病院)から多大なるご協力いただきまし た，ここに，深く感謝の念を表します，なお，本研究は 日本メジフィジックス株式会社との共同研究(PET 装置 及び PET/CT 装置性能評価マニュアル及び当該評価の ための試験解析ソフトの開発研究)によって行ったもの である。

本論文の要旨は，第 67 回日本放射線技術学会総会 学術大会 $(2011$ 年 4 月, 横浜) および第 31 回日本核医 学技術学会総会学術大会(2011 年 10 月, つくば)にて 発表し, 第 67 回日本放射線技術学会総会学術大会で は学術展示賞銅賞を受賞した。

\section{参考文献}

1) Eisenhauer EA, Therasse P, Bogaerts J, et al. New response evaluation criteria in solid tumours: revised RECIST guideline (version 1.1). Eur J Cancer 2009; 45(2): 228-247.

2）日本核医学会．核医学診療事故防止指針，核医 2004; 41(1): i-xxiv.

3) Watanuki S, Tashiro M, Miyake M, et al. Long-term performance evaluation of positron emission tomography: analysis and proposal of a maintenance protocol for long-term utilization. Ann Nucl Med 2010; 24(6): 461-468.

4) 松本圭一, 大崎洋充, 佐藤 敬, 他. 陽電子断層撮影法に おける画質標準化および定量值の精度に関する研究班報 告. 日放技学誌 2009; 65(5): 668-680.

5）日本核医学会。院内製造された FDG 用いたPET 検査を 行うためのガイドライン (第 2 版)。核医 2005; 42(4): 1-22.

6) 庄司安明, 大屋信義, 大崎洋充, 他. FDG-PET 検査に抒 ける撮像技術に関するガイドライン。核医技 2007; 27(5): 425-456.

7）福喜多博義，林万寿夫，鈴木一史，他. がん FDG-PET/CT 撮像法ガイドライン。核医技 2009; 29(2): 195-235.

8）大崎洋充, 島田直毅, 篠原広行. ファントム試験および $\mathrm{NEC}_{\text {density }}$ によるPETイメージングの最適化. Med Imag Tech 2012; 30(5): 250-255.

9）日本核医学会. 分子イメージング戦略会議第二次中間報 告. 2011 年 8 月. (www.jsnm.org/files/pdf/2011/molecule/ molecule_0003.pdf)

10) Daube-Witherspoon ME, Karp JS, Casey ME, et al. PET performance measurements using the NEMA NU 2-2001 standard. J Nucl Med 2002; 43(10): 1398-1409.

11）厚生労働省. 医療法施行規則改正「良質な医療を提供する 体制の確立を図るための医療法等の一部を改正する法律の 一部の施行について」. 医政発第 0330010 号. 平成 19 年 3 月 30 日.

12）一般社団法人日本画像医療システム工業会. PET-CT 診断 装置引渡しにおけるガイドライン。社団法人日本画像医療シ ステム工業会法規・安全部会安全性委員会. 2008.

13) Herzog H, Tellmann L, Hocke C, et al. NEMA NU2-2001 guided performance evaluation of four Siemens ECAT PET scanners. IEEE Trans Nucl Sci 2004; 51(5): 2662-2669.

14) Brix G, Zaers J, Adam LE, et al. Performance evaluation of a whole-body PET scanner using the NEMA protocol. National Electrical Manufacturers Association. J Nucl Med 1997; 38(10): 1614-1623.

15）松本圭一. FDG-PET 検査における撮像技術に関するガイド ラインー性能評価解析ソフトウェアの開発－[abstract]。核 医技 2008; 28(3): 244.

16）松本圭一, 浜田一男, 谷川泰幸. 二種類の FDG-PET ガイ ドラインに対応した解析ソフトウェアの開発。日本放射線技 術学会第 67 回総会学術大会[予稿集]2011: 314.

17）松本圭一, 浜田一男, 谷川泰幸, 他. 2 種類の FDG-PET ガイドラインに対応した解析ソフトウェアの開発。核医技 2011; 31[予稿集], 2011: 308. 